\title{
Large-Scale Processes Associated with Inter-Decadal and Inter-Annual Early Spring Rainfall Variability in Taiwan
}

\author{
Jau-Ming Chen ${ }^{1,2, *}$, Pei-Hua Tan ${ }^{3}$, Ching-Feng Shih ${ }^{4}$, and Hui-Shan Chen ${ }^{1}$ \\ ${ }^{1}$ Department of Maritime Information and Technology, National Kaohsiung Marine University, Kaohsiung, Taiwan, R.O.C. \\ ${ }^{2}$ Department of Oceanography, National Sun Yat-sen University, Kaohsiung, Taiwan, R.O.C. \\ ${ }^{3}$ Department of Applied History, National Chiayi University, Chiayi, Taiwan, R.O.C. \\ ${ }^{4}$ Marine Meteorology Center, Central Weather Bureau, Taipei, Taiwan, R.O.C.
}

Received 8 March 2015, revised 6 May 2015, accepted 17 June 2015

\begin{abstract}
Early spring (March - April) rainfall in Taiwan exhibits evident and distinct inter-annual and inter-decadal variability. The inter-annual varibility has a positive correlation with the El Niño/Southern Oscillation while the inter-decadal variability features a phase change beginning in the late 1970s, coherent with the major phase change in the Pacific decadal oscillation. Rainfall variability in both timescales is regulated by large-scale processes showing consistent dynamic features. Rainfall increases are associated with positive sea surface temperature (SST) anomalies in the tropical eastern Pacific and negative SST anomalies in the tropical central Pacific. An anomalous lower-level divergent center appears in the tropical central Pacific. Via a Rossby-wave-like response, an anomalous lower-level anticyclone appears to the southeast of Taiwan over the Philippine Sea-tropical western Pacific region, which is accompanied by an anomalous cyclone to the north-northeast of Taiwan. Both circulation anomalies induce anomalous southwesterly flows to enhance moisture flux from the South China Sea onto Taiwan, resulting in significant moisture convergence nearby Taiwan. With enhanced moisture supplied by anomalous southwesterly flows, significant rainfall increases occur in both inter-annual and inter-decadal timescales in early spring rainfall on Taiwan.
\end{abstract}

Key words: Early spring rainfall, Inter-annual variability, Inter-decadal variability, Taiwan

Citation: Chen, J.M., P. H.Tan, C.F. Shih, and H.S. Chen, 2016: Large-scale processes associated with inter-decadal and inter-annual early spring rainfall variability in Taiwan. Terr. Atmos. Ocean. Sci., 27, 87-98, doi: 10.3319/TAO.2015.06.17.01(A)

\section{INTRODUCTION}

In spring (March - May) Taiwan is affected by two types of large-scale circulation patterns. The dominant climatic feature is northeasterly flows in early spring (March - April) changing into southwesterly flows in late spring (May). As such, rainfall in May is normally calculated together with rainfall in June. This rainy season is referred to as the Mei-yu season in Taiwan, which corresponds with the salient rainfall mechanism associated with Mei-yu stationary fronts (e.g., Chen 1994; Chen et al. 2010a). On the other hand, major rainfall mechanisms are defined by the passage of frontal systems in early spring induced by the northeast monsoon (e.g., Chen and Chen 2003; Wang and Chen 2008). Some research works have combined rainfall

\footnotetext{
* Corresponding author

E-mail: cjming@mail.nkmu.edu.tw
}

from February to April as spring rainfall (e.g., Jiang et al. 2003; Hung et al. 2004).

Significant rainfall in Taiwan usually occurs in summer due to the Mei-yu systems and typhoons. The associated rainfall characteristics and modulating processes have been broadly analyzed by many studies (e.g., Chen et al. 2005, 2007, 2010b; Hung and Hsu 2008; Chen and Chen 2011; Chou et al. 2011). In contrast, spring rainfall has drawn less research attention probably because of smaller rainfall amounts during this season than during typhoon and Meiyu seasons. It has been found that spring rainfall in Taiwan undergoes notable inter-annual and inter-decadal variability. This inter-annual variability is partially related to the El Niño/Southern Oscillation (ENSO) as ENSO extends its influence from the winter maximum phase into spring during its decaying phase. Jiang et al. (2003) found a positive correlation between the winter Niño-3 sea surface temperature 
(SST) and ensuing spring rainfall over western Taiwan in the period after the late 1970s. Chen et al. (2008) demonstrated that such a positive correlation is concurrent with an evident ENSO-Indian Ocean (IO) connection, featuring in-phase SST anomalies in the tropical eastern Pacific and eastern IO. During an El Niño phase an anomalous lowerlevel anticyclone can occur in the Philippine Sea to induce anomalous southwesterly flows from the South China Sea (SCS) onto Taiwan, leading to increased moisture supply and consequent spring rainfall in Taiwan. Over a longer timescale Hung et al. (2004) found the existence of interdecadal variability in spring rainfall for northern Taiwan. The rainfall amount tends to fluctuate in connection with the Pacific decadal oscillation (PDO; e.g., Mantua et al. 1997), with more spring rainfall during a positive PDO phase and less rainfall during a negative PDO phase. Nevertheless, large-scale ocean-atmospheric processes modulating such inter-decadal rainfall variability have not been comprehensively delineated so far.

The above analyses suggest that rainfall variability during spring in Taiwan is likely systematically regulated by large-scale climate variability in the Asian-Pacific region, such as ENSO and PDO. The PDO is known as an inter-decadal phenomenon in the Pacific with a spatial pattern resembling ENSO, but a very distinct temporal scale (e.g., Zhang et al. 1997). The PDO features two oscillating cycles of 15 - 25 and 50 - 70 years, while ENSO oscillates with a cycle of $2-7$ years (e.g., Minobe 1997, 1999; An and Wang 2000). Spatially, both PDO and ENSO exhibit a pair of reverse-polarity SST anomalies between the tropical eastern Pacific and the extra tropical North Pacific. The SST patterns are dominated by strong extra tropical PDO anomalies and strong tropical ENSO anomalies (e.g., Rasmusson and Carpenter 1982; Rasmusson and Wallace 1983; Philander 1989; Mantua et al. 1997; Zhang et al. 1997). The PDO had a phase change around 1976 - 1977 and this is connected with the most well-known abrupt climate change over the North Pacific during the late-1970s (e.g., Trenberth 1990). It is characterized by strong tropical SST warming in the eastern Pacific (e.g., Nitta and Yamada 1989; Tanimoto et al. 1993; Yasunaka and Hanawa 2003), showing an El Niño-like pattern.

Changes in large-scale climate should influence regional climate. Jiang et al. (2003) demonstrated that ENSO can affect spring rainfall in Taiwan via mid-latitude-tropics interactions. Chen et al. (2008) illustrated that ENSO can either enhance or weaken spring rainfall due to SST distributions in the tropical eastern Pacific and anomalous circulations in the tropical western Pacific, showing an asymmetric effect. Hung et al. (2004) found that SST anomalies in the central-eastern tropical Pacific and accompanying lowertropospheric circulation anomalies in the Philippine Sea are effective in modulating a 20 - 30 years oscillation of spring rainfall in northern Taiwan. Both Jiang et al. (2003) and
Chen et al. (2008) focused on the inter-annual variability, while Hung et al. (2004) focused on the inter-decadal variability. However, the similarity and discrepancy between the inter-annual and inter-decadal variability of spring rainfall in Taiwan have not been systematically investigated. Moreover, the inter-annual variability in spring rainfall previously analyzed corresponds to the ENSO index only, while inter-decadal variability corresponds to the PDO index only. In a different approach, this study uses early spring rainfall variability in Taiwan as the index to directly examine the associated large-scale regulatory processes. The main purpose of this study is to analyze early spring (March - April) rainfall in Taiwan with a focus on portraying and comparing its inter-decadal and inter-annual variability and associated large-scale regulatory processes. Major questions to be addressed are as follows:

(1) What are the major spatiotemporal features of inter-decadal and inter-annual variability in early spring rainfall in Taiwan?

(2) What are the major large-scale processes associated with the aforementioned rainfall variability?

(3) What is the major similarity/discrepancy between the large-scale inter-decadal and inter-annual rainfall variability processes?

Answers to the above questions should help us better understand how large-scale climatic processes regulate local rainfall in the Asian-Pacific region. Such understanding is potentially useful for improving climate prediction in this region.

\section{DATA}

This study analyzes three datasets. Monthly rainfall records from 12 major meteorological stations over Taiwan (Fig. 1) are used to examine inter-decadal and inter-annual variability features of early spring rainfall over the island. The data were obtained from nine stations over the plain areas and three stations over mountains (Table 1), with altitudes ranging from $2-3844 \mathrm{~m}$. Chen et al. (2008) based upon rainfall analysis from 10 stations to show that spring rainfall variability in Taiwan tends to be an island-wide pattern, with major variability features in northern Taiwan. As such, the 12 stations used in this study should be sufficient to delineate the variability patterns covering the Taiwan regions. Ocean climatic features are analyzed from the monthly extended reconstruction SST (ERSST; e.g., Smith and Reynolds 2003, 2004), while atmospheric features are diagnosed from the Twentieth-Century Reanalysis (20CR) monthly data (Compo et al. 2011). The 20CR data are hereafter referred to as the reanalysis data. The ERSST and reanalysis data are jointly used to examine large-scale regulatory ocean-atmospheric processes for local rainfall variability in Taiwan. The analysis period in this study spans from 1950 - 2011. 


\section{CHARACTERISTICS OF EARLY SPRING RAINFALL VARIABILITY IN TAIWAN}

The climatological (1950 - 2011) mean for early spring rainfall accumulated from March to April in Taiwan is shown in Fig. 2a. Chen et al. (2008) demonstrated that the springmean circulation is characterized by a continental high over northern Asia and a Pacific subtropical high (PSH) centering in the subtropical eastern Pacific. The outer flows of the PSH over the western Pacific move warm and moist air along the southeastern coasts of China toward the open oceans south of Japan. These flows encounter cold air from the northeast monsoon from the north to result in frontal activities and rainfall across southeastern China and Taiwan. With frontal activity from the north, Fig. 2a shows that total early spring rainfall is larger over five plain stations in northern Taiwan $(192-349 \mathrm{~mm})$ than four plain stations in southern Taiwan (66 - $123 \mathrm{~mm}$ ). It is also shown that rainfall over three mountainous stations is strong with amounts between 274 to 372 $\mathrm{mm}$. To measure the rainfall variability intensity, root mean square (RMS) values for early spring rainfall during 1950 - 2011 are computed and shown in Fig. 2b. The variability intensity is strong over mountainous stations, followed by northern plain stations and weak in southern plain stations. The spatial patterns of rainfall variability intensity resemble that of total rainfall.

To examine rainfall variability over the island as a whole, an index of early spring rainfall for Taiwan is represented by the rainfall mean from all 12 stations, shown as the dotted lines in Fig. 3a. The time series during the year of 1950 - 2011 are shown as the dotted lines in Fig. 3a. The index time series have a long-term mean of $225 \mathrm{~mm}$ and various variability timescales. To specifically identify the major temporal early spring rainfall modes in Taiwan, the index time series are subject to power spectral analysis. As shown in Fig. 3b the $90 \%$ confidence level (dashed line) indicates two significant temporal modes with peaks near 7.8 and 2.9 years. The appearance of a 2.9-year peak reflects the partial impact of a largescale inter-annual climate feature on early spring rainfall in Taiwan, such as ENSO (e.g., Chen et al. 2008). The 7.8-year peak indicates the existence of a decadal-inter-decadal variability mode. Following the power spectral analysis results, early spring rainfall is thus separated into inter-decadal (larger than 7 years) and inter-annual (2 - 7 years) components for analysis. The inter-decadal components are extracted with a 7-year-running process. The remaining components, computed by removing inter-decadal components from the total rainfall (total minus inter-decadal), are categorized as the inter-annual components. Hereafter, the inter-decadal and inter-annual components of variable $A$ are denoted as $\widetilde{A}$ and $\widehat{A}$, respectively. As shown in Fig. $3 \mathrm{c}$, the inter-annual rainfall $(\widehat{P})$ time series has strong yearly variability. No recognizable inter-decadal fluctuations or trend are embedded in the interannual time series. The inter-decadal rainfall $(\widetilde{P})$ time series are shown in Fig. 3a (thick solid line). They are characterized by having a larger magnitude in the second-half time period than the first-half period, showing two different phases over time to form a noticeable inter-decadal oscillation. It is clear that the inter-annual and inter-decadal components of early spring rainfall in Taiwan are appropriately separated with the approaches used in this study.

\section{INTER-DECADAL RAINFALL VARIABILITY AND LARGE-SCALE REGULATORY PROCESSES}

To investigate major spatiotemporal characteristics of

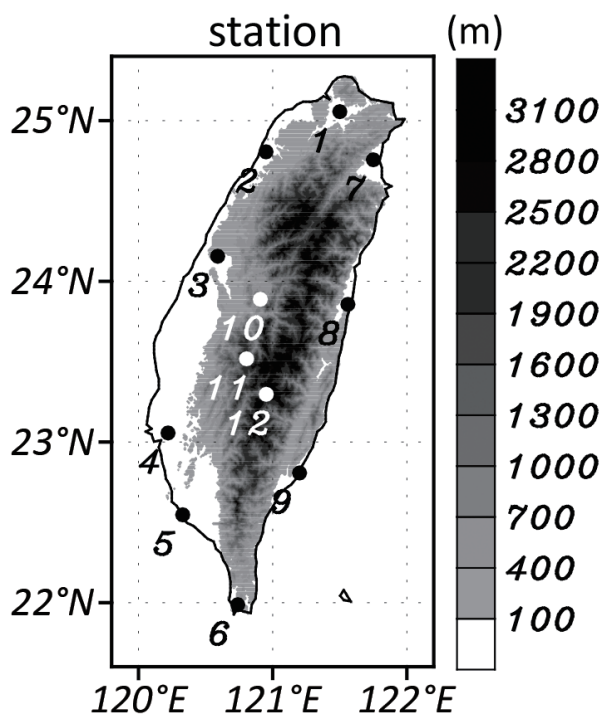

Fig. 1. Geographical distributions of 12 major meteorological stations and topography in Taiwan. Detailed information on these stations are listed in Table 1.

Table 1. Detailed information on the 12 meteorological stations in Taiwan.

\begin{tabular}{rcccc}
\hline No & Station & Longitude & Latitude & Altitude $(\mathbf{m})$ \\
\hline 1 & Taipei & $121.507^{\circ} \mathrm{E}$ & $25.039^{\circ} \mathrm{N}$ & 5.3 \\
2 & Hsinchu & $121.006^{\circ} \mathrm{E}$ & $24.830^{\circ} \mathrm{N}$ & 34 \\
3 & Taichung & $120.676^{\circ} \mathrm{E}$ & $24.147^{\circ} \mathrm{N}$ & 34 \\
4 & Tainan & $120.229^{\circ} \mathrm{E}$ & $23.039^{\circ} \mathrm{N}$ & 8.1 \\
5 & Kaohsiung & $120.308^{\circ} \mathrm{E}$ & $22.568^{\circ} \mathrm{N}$ & 2.3 \\
6 & Hengchun & $120.738^{\circ} \mathrm{E}$ & $22.005^{\circ} \mathrm{N}$ & 22.1 \\
7 & Ilan & $121.748^{\circ} \mathrm{E}$ & $24.766^{\circ} \mathrm{N}$ & 7.2 \\
8 & Hualian & $121.605^{\circ} \mathrm{E}$ & $23.977^{\circ} \mathrm{N}$ & 16 \\
9 & Taitung & $121.146^{\circ} \mathrm{E}$ & $22.754^{\circ} \mathrm{N}$ & 9 \\
10 & Jihyuehtan & $120.908^{\circ} \mathrm{E}$ & $23.881^{\circ} \mathrm{N}$ & 1014.8 \\
11 & Alishan & $120.805^{\circ} \mathrm{E}$ & $23.510^{\circ} \mathrm{N}$ & 2413.4 \\
12 & Yushan & $120.952^{\circ} \mathrm{E}$ & $23.489^{\circ} \mathrm{N}$ & 3844.8 \\
\hline
\end{tabular}


(a) mean

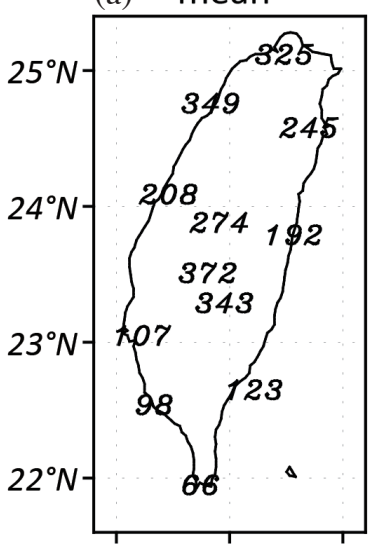

$120^{\circ} \mathrm{E} \quad 121^{\circ} \mathrm{E} \quad 122^{\circ} \mathrm{E} 120^{\circ} \mathrm{E} \quad 121^{\circ} \mathrm{E} \quad 122^{\circ} \mathrm{E}$ (b) $\quad \mathrm{rms}$

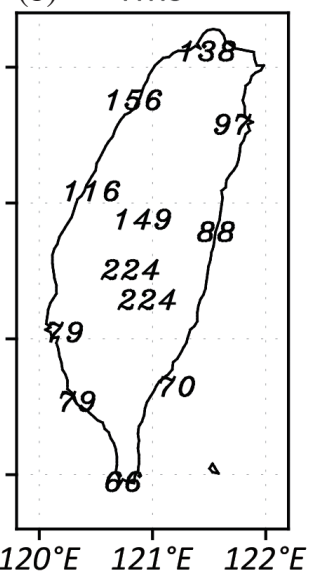

Fig. 2. The (a) climatological mean and (b) root mean square (RMS) value of total early spring (March - April) rainfall in Taiwan during 1950 2011, unit: $\mathrm{mm}$.
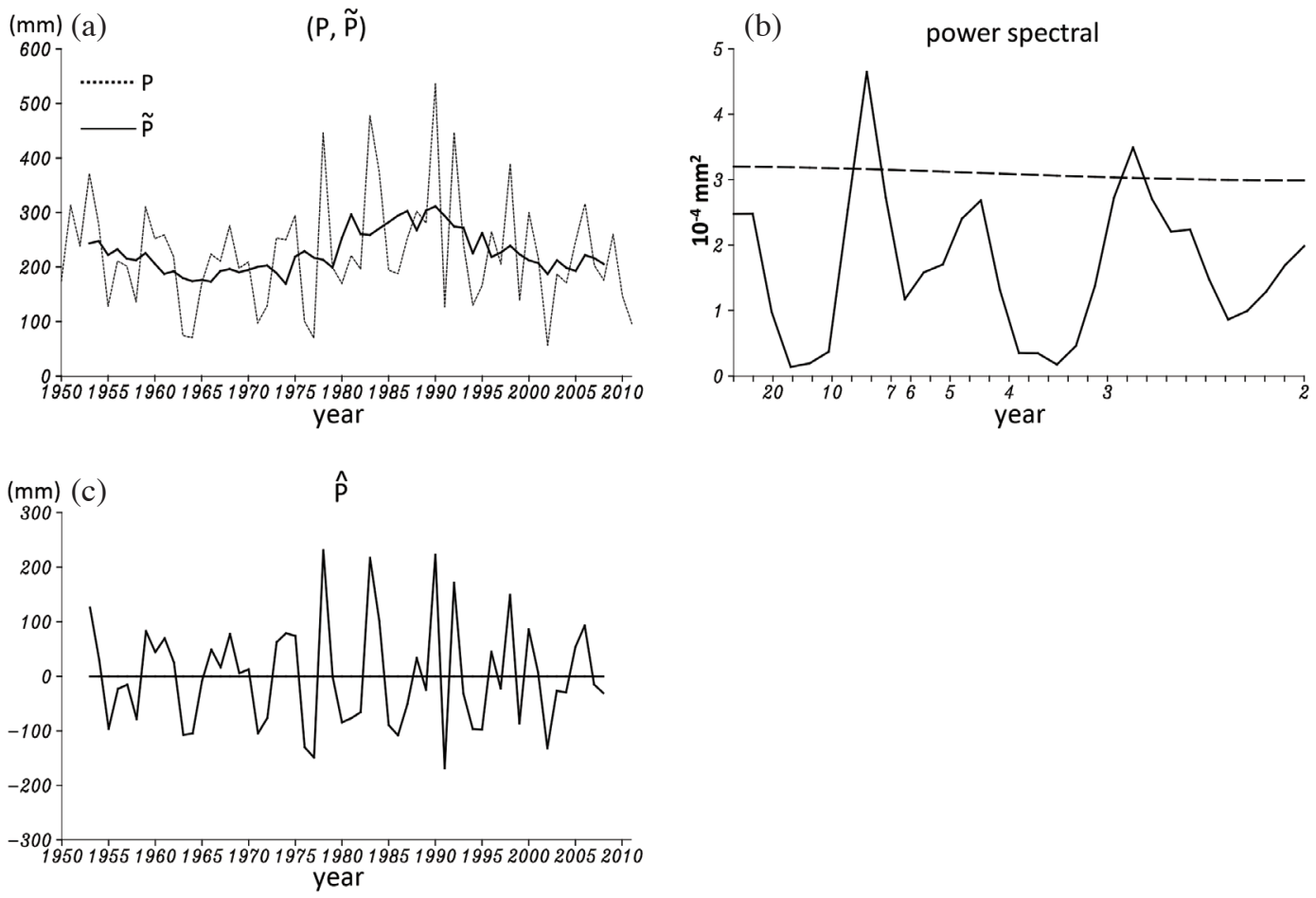

Fig. 3. (a) The time series of year 1950 - 2011 of early spring rainfall index in Taiwan (dashed line) and the inter-decadal time series (dark solid line). (b) Power spectral analysis of the 1950 - 2011 time series of rainfall index. The $90 \%$ confidence level is indicated by the dashed line. (c) Time series of inter-annual components of early spring rainfall.

inter-decadal variability in early spring rainfall, the interdecadal rainfall components from Taiwan's 12 stations are subject to empirical orthogonal function (EOF) analysis. The first Eigen mode accounts for $78 \%$ of inter-decadal rainfall variance from these stations. The spatial variability (the first eigenvector, E1) in Fig. 4a exhibits positive anomalies at most stations, with two near-zero negative anomalies in eastern Taiwan. The positive anomalies are strong in the northern plains and mountainous regions and moderate in southwestern Taiwan. The corresponding temporal variability (the first principal component, C1) in Fig. 4b exhibits a clear inter-decadal fluctuation with a generally negative phase before 1980, a generally positive phase during the 1980s and 1990s, and a weak negative phase after 2000. The simultaneous correlation coefficients between the $\mathrm{C} 1$ time series and $\widetilde{P}$ time series in Fig. 3a is 0.98 . These results 
demonstrate that the first Eigen mode is representative of inter-decadal variability for early spring rainfall in Taiwan.

The large-scale processes regulating inter-decadal rainfall variability are interpreted from the correlation patterns corresponding to the $\widetilde{P}$ time series in Fig. 3a. The inter-decadal components of large-scale variables are extracted using the same processes as those used for early spring rainfall in Taiwan. To consider a reduction in degrees of freedom for the inter-decadal variables after running process application, the effective degrees of freedom used by Davis (1976) and Chen (1982) were employed to perform a statistical significance test. The effective degrees of freedom $(N)$ are computed as $n / T$, where $n$ is the number of sample observations (62 in the analysis with the $1950-2011$ period), and $T=\sum_{\tau=0}^{K} C_{x x}(\tau) C_{y y}(\tau)$ between two correlated fields. $C_{x x}(\tau)$ and ${ }^{\tau} C_{y y}^{0}(\tau)$ are the autocorrelation coefficients of variables $x_{i}(i=1, \ldots, n)$ and $y_{i}(i=1, \ldots, n)$, respectively, with a time lag of $\tau$. The maximum time lag $K$ corresponds to $n / 2$.

The SST correlation patterns and atmospheric circulations with respect to the $\widetilde{P}$ time series are shown in Fig. 5, and the correlation patterns significant at the 0.05 level are shaded. As indicated by the shaded patterns, tropical SSTs exhibit significant negative anomalies in the central Pacific near the dateline with a northward extension to the extra tropical $\mathrm{Pa}$ cific. The significant positive anomalies appear eastward over the eastern Pacific and westward over the eastern IO-SCS region. Atmospheric circulation responses to underlying SST anomalies are depicted by 850 -hPa velocity potential (X850) and streamfunction (S850). The negative SST anomalies in the central tropical and extra tropical Pacific cause the overlying atmosphere to form a significant large-scale divergent (negative X850) anomaly (Fig. 5b). Meanwhile, convergent (positive X850) centers appear over the eastern Pacific and IO corresponding to positive SST anomalies. Both cold SST and large-scale divergent centers in the central Pacific act as tropical forcing to induce a Rossby-wave-like response (e.g., Matsuno 1966; Gill 1980) in $S 850$ anomalies. As shown in Fig. 5c the response appears as a meridional pair of anticyclonic anomalies straddling the Equator to the west of the anomalous divergent center and a pair of cyclonic anomalies to the east. As such, an anomalous anticyclone is located to the southeast of Taiwan accompanied by an anomalous cyclone to the north-northeast of Taiwan. This pair of significant anticyclonic and cyclonic anomalies should exert major impacts on inter-decadal rainfall variability in Taiwan.

The atmospheric hydrological processes are the key factors in modulating rainfall variability. Three moisture variables are analyzed: vertically-integrated moisture flux ( $V_{Q}=\int_{p}^{p_{0}} \vec{V} q d p$, where $\vec{V}$ is the horizontal wind vector, $q$ is specific humidity and the vertical integral is from a given pressure level to $\left.p_{0}=1000 \mathrm{hPa}\right)$, precipitable water $(W)$, and moisture flux divergence $\left(\nabla \cdot V_{Q}\right)$. The correlation patterns of these three variables with respect to the $\widetilde{P}$ time series are shown in Fig. 6. The significant $\widetilde{V}_{Q}$ patterns in Fig. $6 a$ reveal that major moisture flux paths extend northeastward from the SCS onto Taiwan. They are transported along the northwestern boundary of an anomalous anticyclone to the southeast of Taiwan over the tropical western Pacific. These $\widetilde{V}_{Q}$ anomalies cross Taiwan to merge with westerly $\widetilde{V}_{Q}$ anomalies along the southern boundary of an anomalous cyclone to the north-northeast of Taiwan. Excessive moisture flux from the SCS onto Taiwan intensifies atmospheric moisture content, leading to significant positive $\widetilde{W}$ anomalies over the northern SCS and Taiwan (Fig. 6b). The northeastward transport of moist and warm air from the SCS encounters cold air in the northern region. Frontal systems and accompanying significant moisture convergence (negative $\nabla \cdot \widetilde{V}_{Q}$ ) anomalies thus occur in the region extending from Taiwan into Japan (Fig. 6c). Enhancements in moisture supply and moisture convergence around Taiwan correspond to significant inter-decadal increases in early spring rainfall in Taiwan. The most important process appears as a pair of lower-level circulation anomalies sandwiching Taiwan to maintain excessive moisture transport via anomalous southwesterly flows from the SCS onto Taiwan.

\section{INTER-ANNUAL RAINFALL MODE AND REGULATORY PROCESSES}

The inter-annual components of spring rainfall from 12 Taiwan stations are subject to EOF analysis. The first mode accounts for $76 \%$ of the total inter-annual variance. Its spatial patterns exhibit positive anomalies throughout the island with the strongest magnitudes over mountainous stations. Rainfall anomalies are stronger in northern Taiwan than southern Taiwan (Fig. 7a). Its temporal variability, as indicated by the $\mathrm{C} 1$ time series in Fig. 7b, exhibits dominant year-to-year variability features. The $\mathrm{C} 1$ time series has a correlation coefficient of 0.92 with the $\widehat{P}$ time series in Fig. 3c. This mode is representative of the major inter-annual variability in early spring rainfall in Taiwan.

The associated large-scale processes regulating interannual rainfall variability are examined from the correlation patterns with respect to the $\widehat{P}$ time series in Fig. $3 \mathrm{c}$. The inter-annual components of large-scale variables are extracted using the same processes applied to inter-annual rainfall components in Taiwan. The correlated SST patterns exhibit significant negative anomalies in the tropical central Pacific. They form a horseshoe-like pattern that surrounds significant positive anomalies in the tropical eastern Pacific. Consequently, significant centers of large-scale divergent (negative X850) and convergent (positive X850) anomalies appear in the central and eastern Pacific, respectively. The central-Pacific divergent anomalies extend from the extra tropics into the tropics and act as an effective tropical forcing to induce a Rossby-wave-like response in $S 850$ anomalies. As shown in Fig. 8c a pair of lower-level anticyclonic circulations across the Equator is located to the west of the divergent center, 
while a pair of cyclonic circulations is situated to the east of the center. A significant anomalous anticyclone appears to the southeast of Taiwan, centering over the Philippine Seatropical western Pacific region. It is accompanied by an elon- gated anomalous cyclone across China and Japan. Taiwan is thus surrounded by an anomalous cyclone to the north and an anomalous anticyclone to the southeast.

In terms of hydrological processes, the above
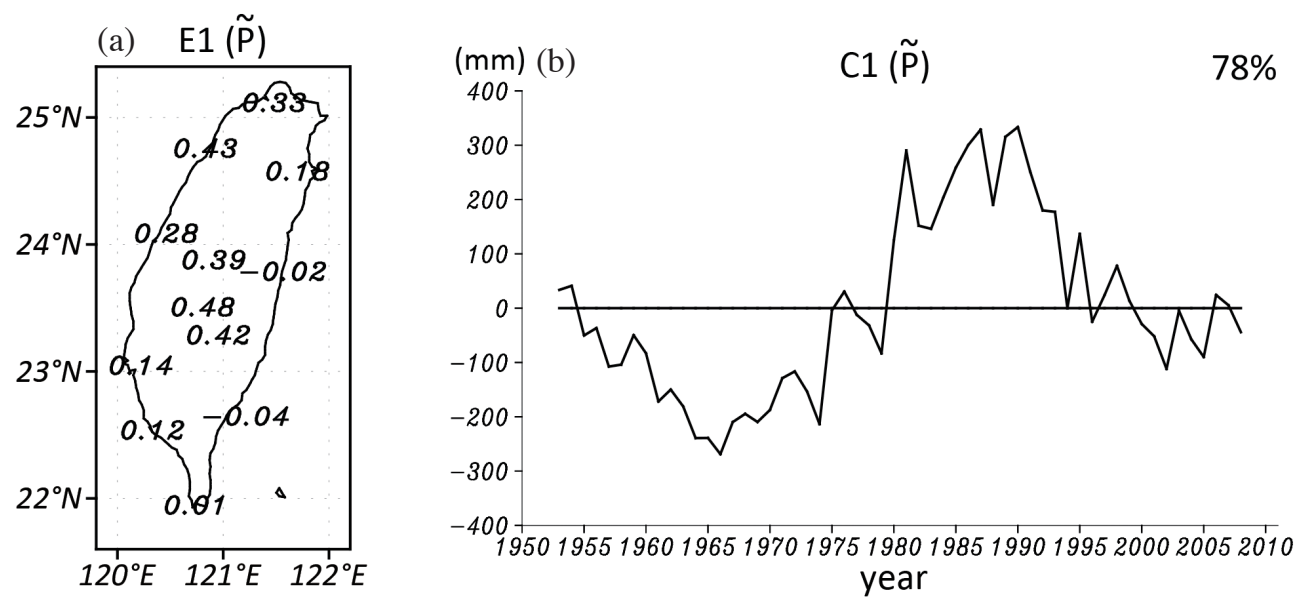

Fig. 4. The first Eigen mode of inter-decadal components of early spring rainfall in Taiwan: (a) the first eigenvector (E1), and (b) the first principal components $(\mathrm{C} 1)$. This mode accounts for $78 \%$ of total inter-decadal rainfall variance.

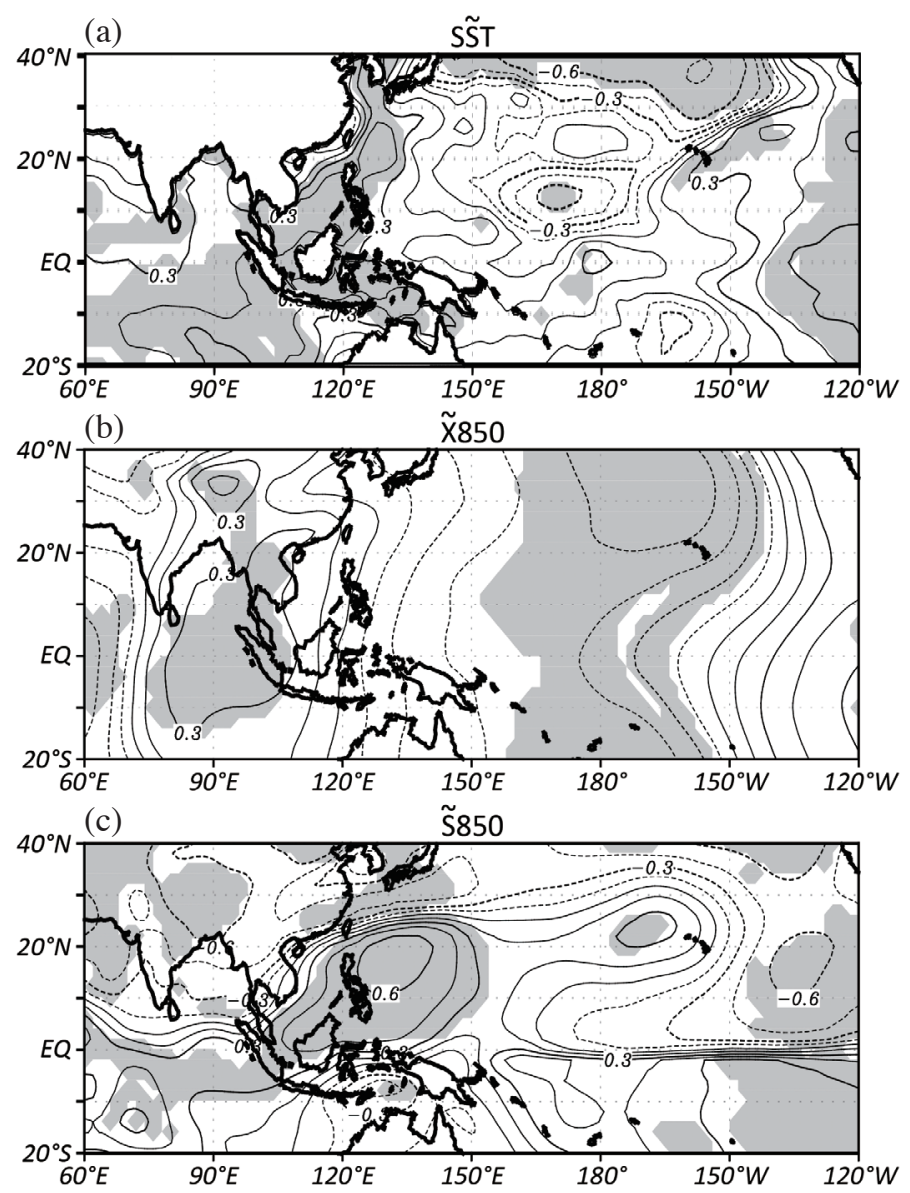

Fig. 5. With respect to the inter-decadal rainfall time series in Fig. 3a, the correlation coefficient patterns of inter-decadal anomalies of (a) SST, (b) $850-\mathrm{hPa}$ velocity potential (X850), and (c) $850-\mathrm{hPa}$ streamfunction (S850). Correlation patterns significant at the 0.05 level are shaded. Contour intervals are 0.15 . 

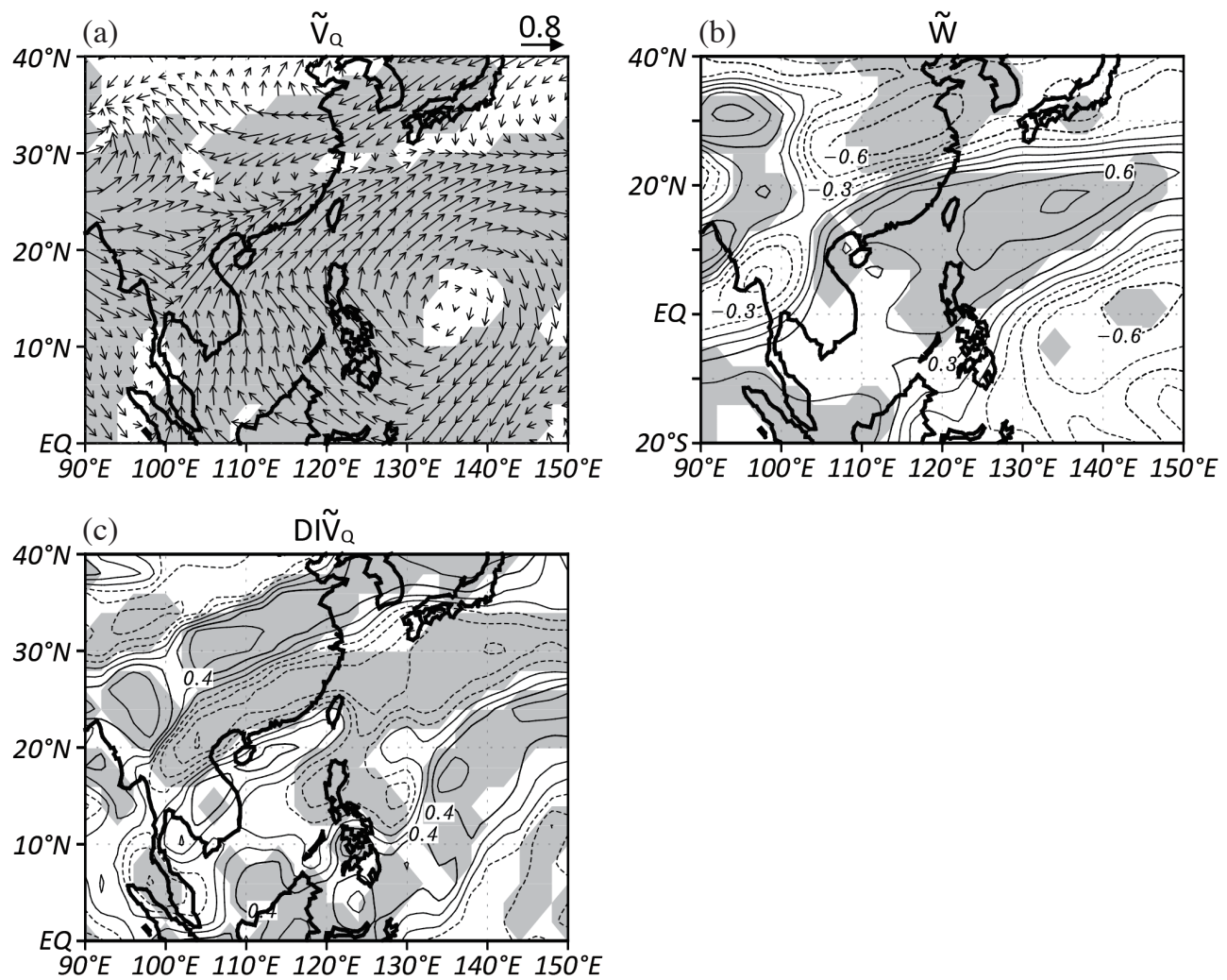

Fig. 6. As in Fig. 5, except for the correlation coefficient patterns of inter-decadal anomalies of (a) moisture flux $\left(V_{Q}\right)$, (b) precipitable water $(W)$, and (c) moisture flux divergence $\left(\nabla \cdot V_{Q}\right)$. Correlation patterns significant at the 0.05 level are shaded. Contour intervals are 0.15 in (b) and 0.2 in (c).
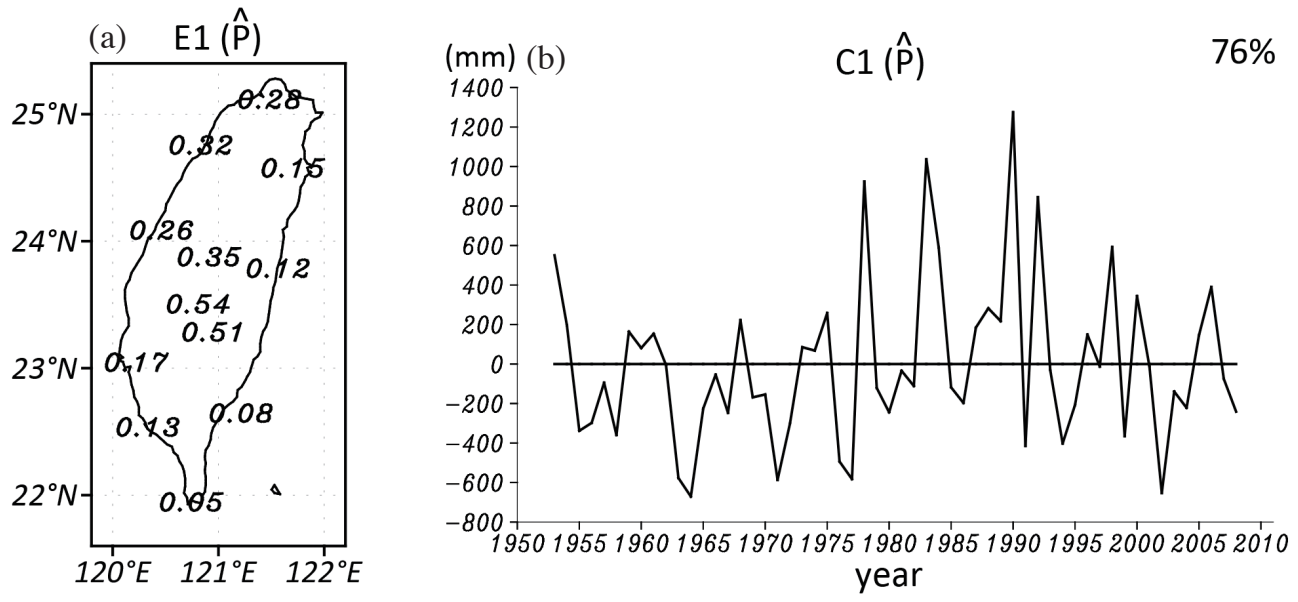

Fig. 7. The first Eigen mode of inter-annual components of early spring rainfall in Taiwan: (a) the first Eigen-vector (E1), and (b) the first principal components $(\mathrm{C} 1)$. This mode accounts for $76 \%$ of total inter-annual rainfall variance. 


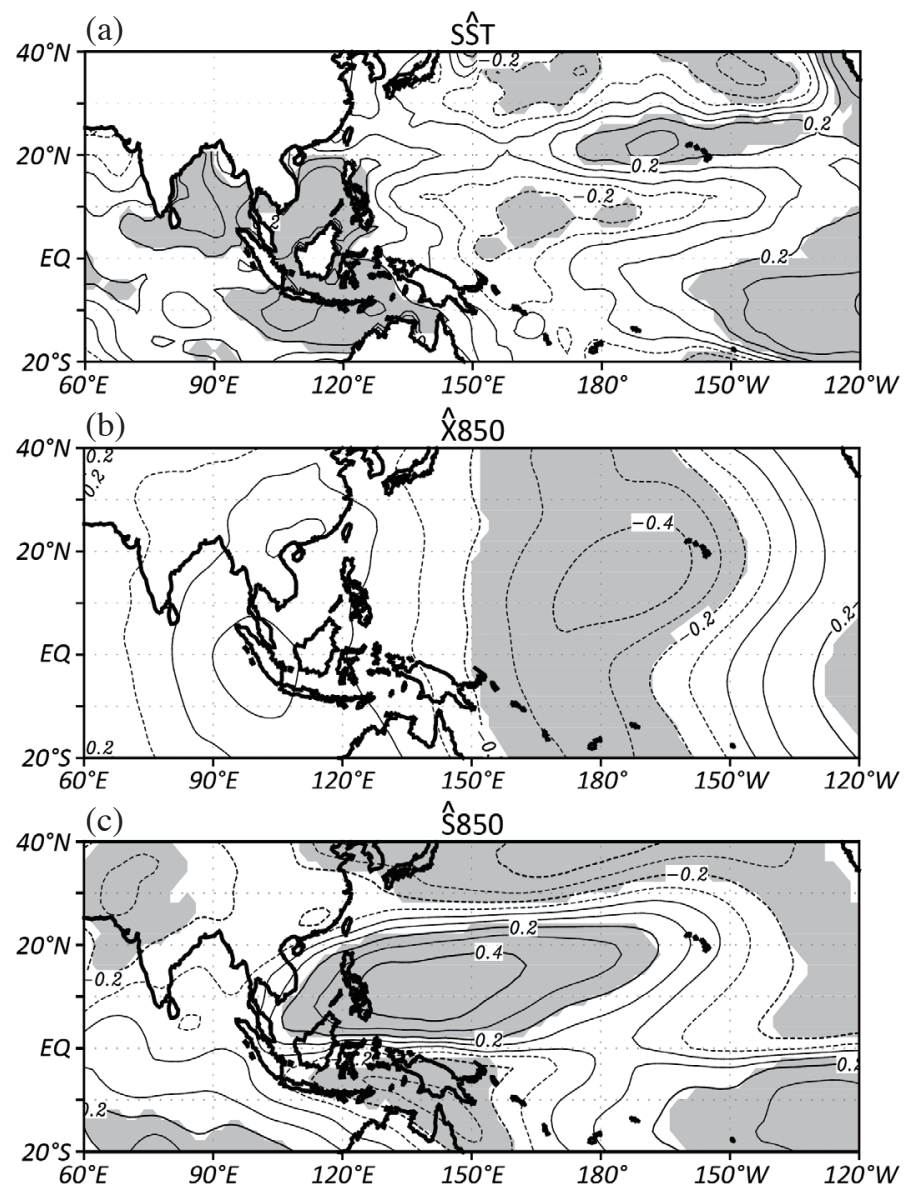

Fig. 8. With respect to the inter-annual rainfall time series in Fig. 3c, the correlation coefficient patterns of inter-annual anomalies of (a) SST, (b) 850 -hPa velocity potential (X850), and (c) 850-hPa streamfunction (S850). Correlation patterns significant at the 0.05 level are shaded. All contour intervals are 0.1 .

circulation anomalies affect Taiwan with significant southwesterly $\widetilde{V}_{Q}$ anomalies from the SCS onto Taiwan (Fig. 9a). They are jointly transported by an anomalous anticyclone to the southeast of Taiwan and an anomalous cyclone to the north of Taiwan. Along with this moisture flux, significant positive $\widehat{W}$ anomalies stretch from the northern SCS across Taiwan toward the northwestern Pacific (Fig. 9b). The excessive moisture supply from the south encounters seasonal cold air from the north to result in significant moisture convergence (negative $\nabla \cdot \widehat{V}_{Q}$ ) anomalies elongating from southern China toward Taiwan, leading to increases in early spring rainfall over Taiwan. The major large-scale mechanisms regulating the inter-annual variability in early spring rainfall in Taiwan appear as moisture processes induced by a pair of opposite-polarity circulation anomalies to the southeast and to the north of Taiwan.

\section{COMPARISON OF INTER-DECADAL AND INTER-ANNUAL RAINFALL VARIABILITY}

As revealed by the above analyses of SSTs, atmo- spheric circulations, and hydrological variables, inter-decadal and inter-annual variability in early spring rainfall in Taiwan and the associated large-scale regulatory processes exhibit some common features. These features are schematically illustrated in Fig. 10. Increases in early spring rainfall are maintained by significant anomalous moisture fluxes to enhance moisture convergence near Taiwan. The increased moisture supply is carried by anomalous southwesterly flows (black arrow) from the SCS onto Taiwan. These flows are jointly induced by an anomalous anticyclone (AC) to the southeast of Taiwan and an anomalous cyclone (C) to the north-northeast of Taiwan. The anomalous anticyclone owes its existence to a Rossby-wave-like response of lowertropospheric atmospheric circulation to tropical forcing related to an anomalous divergent center (DIV) and cold SST anomalies in the tropical central Pacific. Meanwhile, warm SST anomalies appear in the tropical eastern Pacific. It is clear that early spring rainfall variability in both inter-annual and inter-decadal timescales in Taiwan is regulated by similar large-scale processes from the ocean-atmospheric system in the Asia-Pacific region. 
Regarding inter-annual variability, the most significant inter-annual feature in the Pacific is ENSO. The SST anomalies associated with inter-annual rainfall variability bear the signature of an El Niño pattern. As shown in Fig. 8a SSTs exhibit strong and elongated positive anomalies in the tropical eastern Pacific, which is surrounded by horseshoe-like negative anomalies in the central and western Pacific. The appearance of a lower-tropospheric anomalous anticyclone in the Philippine Sea (Fig. 8c) reflects remote impacts from ENSO on the East Asian climate (e.g., Wang et al. 2000; Wang and Zhang 2002). The simultaneous cor- relation coefficient between the $\widehat{P}$ time series (Fig. 3c) and February - April Niño-3 SST time series constructed by the Climate Prediction Center (CPC) of National Oceanic and Atmospheric Administration (NOAA) is 0.28. This is statistically significant at the 0.05 level. This result suggests the ENSO events exert partial remote impacts on inter-annual variability in spring rainfall over Taiwan.

On an inter-decadal timescale, inter-decadal rainfall variability in Taiwan shows a phase change beginning in the late 1970s (Fig. 4a). The associated SST anomalies feature strong SST warming in the tropical eastern Pacific
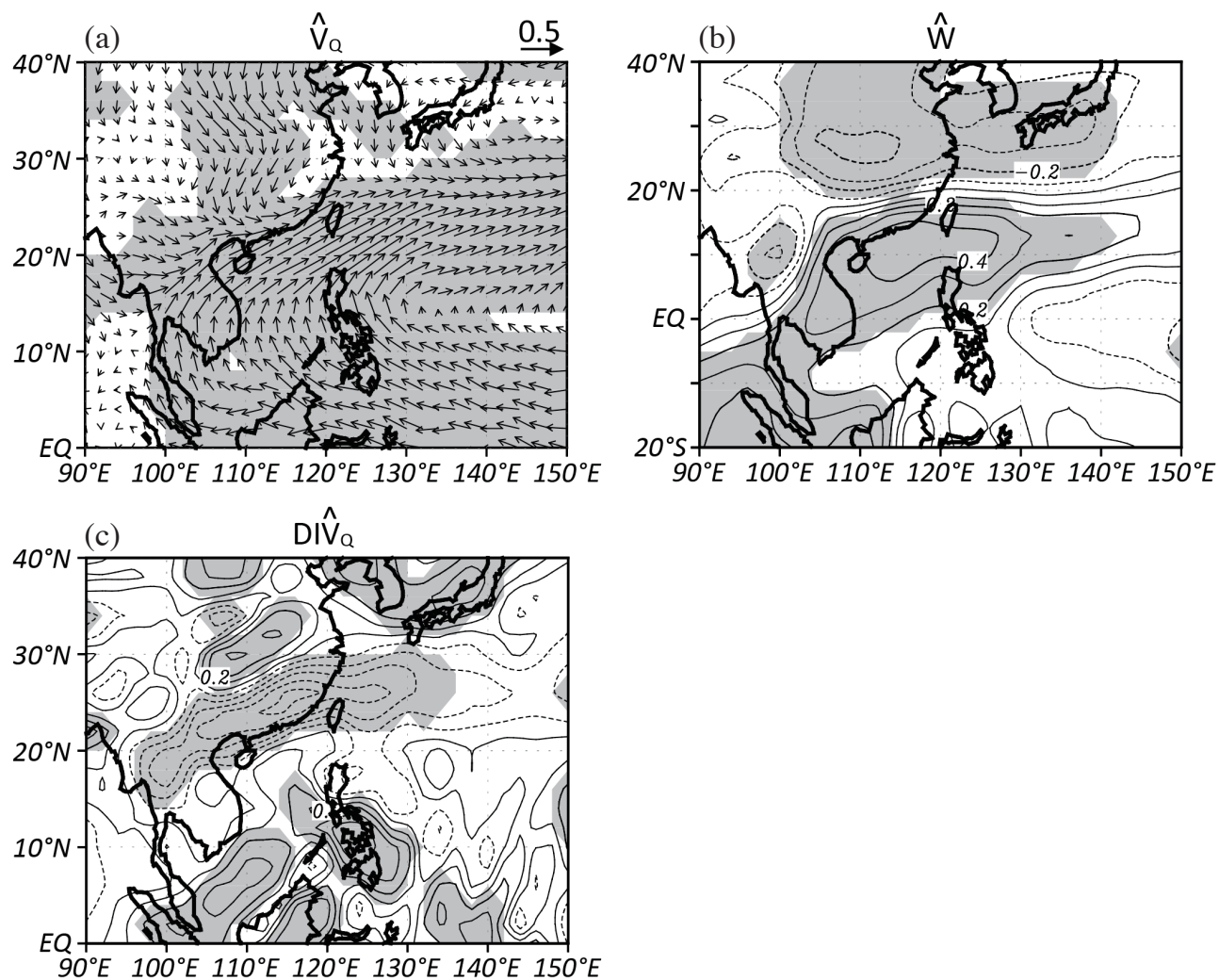

Fig. 9. As in Fig. 8, except for the correlation coefficient patterns of inter-annual anomalies of (a) moisture flux $\left(V_{\mathrm{Q}}\right)$, (b) precipitable water $(W)$, and (c) moisture flux divergence $\left(\nabla \cdot V_{Q}\right)$. Correlation patterns significant at the 0.05 level are shaded. All contour intervals are 0.1 .

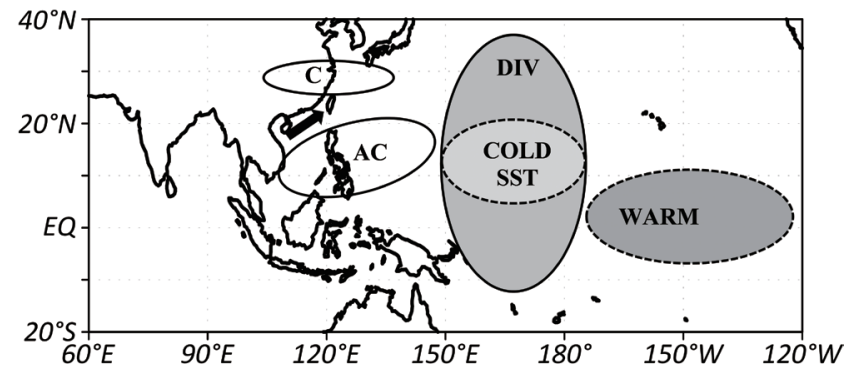

Fig. 10. Schematic illustration for the major regulating processes of inter-decadal and inter-annual variability of early spring rainfall in Taiwan. Tropical warm SST anomalies in the eastern Pacific and cold SST anomalies in the central Pacific act to induce a divergent center (DIV) in the central Pacific, which in turn excites a lower-level anomalous anticyclone (AC) to the southeast of Taiwan, which is accompanied by an anomalous cyclone (C) to the north-northeast of Taiwan. These circulation anomalies induce anomalous southwesterly flows (black arrow) to enhance moisture flux from the SCS onto Taiwan, leading to increased early spring rainfall in Taiwan. 
and cooling in the extra tropical North Pacific and tropical central Pacific (Fig. 5a), resembling the salient features of the PDO (e.g., Mantua et al. 1997; Gershunov and Barnett 1998; Hare et al. 1999; McCabe and Dettinger 1999; Meehl et al. 2009). The PDO is known for an inter-decadal phase change in SST anomalies during the late 1970s, coherent with the inter-decadal rainfall variability feature in Taiwan. The simultaneous correlation coefficient between the PDO index time series (constructed by the National Climatic Data Center, NOAA) and inter-decadal rainfall variability in Taiwan (Fig. 3a) is 0.61 , with effective degrees of freedom around 11 . This correlation is statistically significant at the 0.05 level. This suggests that inter-decadal variability in early spring rainfall in Taiwan has occurred in relation to the PDO evolution.

\section{CONCLUDING REMARKS}

This study analyzed inter-decadal and inter-annual variability in early spring (March - April) rainfall in Taiwan, with a focus on delineating and comparing the major spatiotemporal features and associated large-scale regulatory processes. The inter-decadal components of spring rainfall were extracted as the 7-year-running mean. The differences between total rainfall and inter-decadal components (total minus inter-decadal) were categorized as the inter-annual components. Observational rainfall from 12 Taiwan stations for the period of 1950 - 2011 was subject to EOF analysis. The major inter-decadal (inter-annual) rainfall mode was examined from the first EOF mode, which is representative of the major inter-decadal (inter-annual) rainfall variability accounting for $78 \%$ (76\%) of total inter-decadal (inter-annual) variances.

Rainfall variability on inter-decadal and inter-annual timescales exhibits distinct temporal features, but relatively coherent spatial patterns and large-scale regulatory processes. The inter-decadal rainfall variability features a phase change beginning in the late 1970s. For inter-annual rainfall variability, its temporal variability has a positive correlation with the ENSO SST index. Both inter-decadal and inter-annual rainfall variability exhibits stronger anomalies in the mountains than in the plains and in northern Taiwan than in southern Taiwan. For the coherent large-scale regulatory process features, increased rainfall in both timescales corresponds to positive SST anomalies in the tropical eastern Pacific and negative SST anomalies in the tropical central Pacific. These anomalous SSTs induce a large-scale divergent center in the tropical central Pacific which acts as a tropical forcing to cause a Rossby-wave-like response in the atmospheric circulation. An anomalous anticyclone thus appears to the southeast of Taiwan over the Philippine Sea-tropical western Pacific region, which is accompanied by an anomalous cyclone to the north-northeast of Taiwan. Taiwan is sandwiched between this pair of circulation anomalies and affected by anomalous southwesterly flows. These anomalous flows transport moisture from the SCS onto Taiwan. Excessive moisture supplies and enhanced moisture convergence around Taiwan lead to increased early spring rainfall for both inter-decadal and inter-annual variability in Taiwan.

Moisture flux by anomalous southwesterly flows associated with an anomalous anticyclone over the Philippine Sea-tropical western Pacific region is the key factor affecting early spring rainfall variability in Taiwan on both inter-decadal and inter-annual timescales. The appearance of an anomalous anticyclone over the Philippine Sea was found as a salient feature of El Niño (e.g., Wang et al. 2000; Wang and Zhang 2002). After the late-1970s climate shift, inter-decadal components of early spring rainfall in Taiwan changed from a negative phase into a positive phase. Meanwhile, the large-scale climate anomalies exhibited a positive PDO phase, featuring an El Niño-like pattern (e.g., Mantua et al. 1997). The above results reveal that an El Niño-like climate pattern on inter-annual and inter-decadal timescales provides favorable conditions for early spring rainfall to increase in Taiwan.

The inter-decadal variability in early spring rainfall changes into a negative phase in the early 2000s, as revealed by the $\mathrm{C} 1$ time series in Fig. 4b. Hartmann and Wendler (2005) showed that the positive PDO phase lasted for 25 years from 1977 - 2001, and moved toward a negative phase in the early 2000s. As so, early spring rainfall in Taiwan is likely to recede following the phase change in the PDO. This tendency toward a drier spring climate after 2000 can be clearly seen in the inter-decadal time series of early spring rainfall in Fig. 2a (thick solid lines). Given this condition, the PDO can be used as a potentially useful index for projecting inter-decadal oscillation in early spring rainfall in Taiwan. Such a projection plus the projecting of global warming on regional rainfall should be of help to water resource management in Taiwan when facing the impacts of extreme weather from future climate change.

Acknowledgements The authors thank the anonymous reviewers for their valuable comments, which helped improve the quality of this paper. This study was supported by Ministry of Science and Technology, Taiwan, under Grants: MOST 103-2111-M-022-001 and MOST 103-2111-M-415-001.

\section{REFERENCES}

An, S.I. and B. Wang, 2000: Interdecadal change of the structure of the ENSO mode and its impact on the ENSO frequency. J. Climate, 13, 2044-2055, doi: 10.1175/15200442(2000)013<2044:ICOTSO>2.0.CO;2. [Link]

Chen, C. S. and Y. L. Chen, 2003: The rainfall characteristics of Taiwan. Mon. Weather Rev., 131, 1323-1341, doi: 10.1175/1520-0493(2003)131<1323:TRCOT>2.0 .CO;2. [Link] 
Chen, C. S., Y. L. Chen, C. L. Liu, P. L. Lin, and W. C. Chen, 2007: Statistics of heavy rainfall occurrences in Taiwan. Weather Forecast., 22, 981-1002, doi: 10.1175/WAF1033.1. [Link]

Chen, G. T. J., 1994: Large-scale circulations associated with the East Asian summer monsoon and the Mei-yu over South China and Taiwan. J. Meteorol. Soc. Jpn., 72, 959-983.

Chen, J. M. and H. S. Chen, 2011: Interdecadal variability of summer rainfall in Taiwan associated with tropical cyclones and monsoon. J. Climate, 24, 5786-5798, doi: 10.1175/2011JCLI4043.1. [Link]

Chen, J. M., F. C. Lu, S. L. Kuo, and C. F. Shih, 2005: Summer climate variability in Taiwan and associated largescale processes. J. Meteorol. Soc. Jpn., 83, 499-516, doi: 10.2151/jmsj.83.499. [Link]

Chen, J. M., T. Li, and C. F. Shih, 2008: Asymmetry of the El Niño-spring rainfall relationship in Taiwan. J. Meteorol. Soc. Jpn., 86, 297-312, doi: 10.2151/jmsj.86.297. [Link]

Chen, J. M., J. L. Chu, C. F. Shih, and Y. C. Tung, 2010a: Interannual variability of circulation-rainfall relationship in Taiwan during the Mei-yu season. Int . J. Climatol., 30, 2264-2276, doi: 10.1002/joc.2049. [Link]

Chen, J. M., T. Li, and C. F. Shih, 2010b: Tropical cycloneand monsoon-induced rainfall variability in Taiwan. $J$. Climate, 23,4107-4120, doi: 10.1175/2010JCLI3355.1. [Link]

Chen, W. Y., 1982: Fluctuations in Northern Hemisphere 700 mb height field associated with the Southern Oscillation. Mon. Weather Rev., 110, 808-823, doi: 10.1175/15200493(1982)110<0808:FINHMH>2.0.CO;2. [Link]

Chou, M. D., C. H. Wu, and W. S. Kau, 2011: Large-scale control of summer precipitation in Taiwan. J. Climate, 24, 5081-5093, doi: 10.1175/2011JCLI4057.1. [Link]

Compo, G. P., J. S. Whitaker, P. D. Sardeshmukh, N. Matsui, R. J. Allan, X. Yin, B. E. Gleason Jr., R. S. Vose, G. Rutledge, P. Bessemoulin, S. Brönnimann, M. Brunet, R. I. Crouthamel, A. N. Grant, P. Y. Groisman, P. D. Jones, M. C. Kruk, A. C. Kruger, G. J. Marshall, M. Maugeri, H. Y. Mok, Ø. Nordli, T. F. Ross, R. M. Trigo, X. L. Wang, S. D. Woodruff, and S. J. Worley, 2011: The twentieth century reanalysis project. Q.J.R. Meteorol. Soc., 137, 1-28, doi: 10.1002/qj.776. [Link]

Davis, R. E., 1976: Predictability of sea surface temperature and sea level pressure anomalies over the North Pacific Ocean.J. Phys. Oceanogr., 6, 249-266, doi: 10.1175/15 20-0485(1976)006<0249:possta>2.0.co;2. [Link]

Gershunov, A. and T. P. Barnett, 1998: Interdecadal modulation of ENSO teleconnections. Bull. Amer. Meteorol. Soc., 79, 2715-2725, doi: 10.1175/1520-0477(1998)079<2715:imoet>2.0.co;2. [Link]

Gill, A. E., 1980: Some simple solutions for heat-induced tropical circulation. Q. J.R. Meteorol. Soc., 106, 447-
462, doi: 10.1002/qj.49710644905. [Link]

Hare, S. R., N. J. Mantua, and R. C. Francis, 1999: Inverse production regimes: Alaska and west coast Pacific salmon. Fisheries, 24, 6-14, doi: 10.1577/1548-8446(1999)024<0006:IPR>2.0.CO;2. [Link]

Hartmann, B. and G. Wendler, 2005: The significance of the 1976 Pacific climate shift in the climatology of Alaska. J. Climate, 18, 4824-4839, doi: 10.1175/JCLI3532.1. [Link]

Hung, C. W. and H. H. Hsu, 2008: The first transition of the Asian summer monsoon, intraseasonal oscillation, and Taiwan Mei-yu. J. Climate, 21, 1552-1568, doi: 10.1175/2007JCLI1457.1. [Link]

Hung, C. W., H. H. Hsu, and M. M. Lu, 2004: Decadal oscillation of spring rain in northern Taiwan. Geophys. Res. Lett., 31, L22206, doi: 10.1029/2004GL021344. [Link]

Jiang, Z., G. T. J. Chen, and M. C. Wu, 2003: Large-scale circulation patterns associated with heavy spring rain events over Taiwan in strong ENSO and non-ENSO years. Mon. Weather Rev., 131, 1769-1782, doi: 10.1175//2561.1. [Link]

Mantua, N. J., S. R. Hare, Y. Zhang, J. M. Wallace, and R. C. Francis, 1997: A Pacific interdecadal climate oscillation with impacts on salmon production. Bull. Amer. Meteorol. Soc., 78, 1069-1079, doi: 10.1175/15200477(1997)078<1069:APICOW>2.0.CO;2. [Link]

Matsuno, T., 1966: Quasi-geostrophic motions in the equatorial area. J. Meteorol. Soc. Jpn., 44, 25-43.

McCabe, G. J. and M. D. Dettinger, 1999: Decadal variations in the strength of ENSO teleconnections with precipitation in the western United States. Int. J. Climatol., 19, 1399-1410, doi: 10.1002/(SICI)1097-0088(19991115)19:13<1399::AID-JOC457>3.0.CO;2-A. [Link]

Meehl, G. A., A. Hu, and B. D. Santer, 2009: The mid-1970s climate shift in the Pacific and the relative roles of forced versus inherent decadal variability. J. Climate, 22, 780-792, doi: 10.1175/2008JCLI2552.1. [Link]

Minobe, S., 1997: A 50-70 year climatic oscillation over the North Pacific and North America. Geophys. Res. Lett., 24, 683-686, doi: 10.1029/97GL00504. [Link]

Minobe, S., 1999: Resonance in bidecadal and pentadecadal climate oscillations over the North Pacific: Role in climatic regime shifts. Geophys. Res. Lett., 26, 855-858, doi: 10.1029/1999GL900119. [Link]

Nitta, T. and S. Yamada, 1989: Recent Warming of tropical sea surface temperature and its relationship to the Northern Hemisphere circulation. J. Meteorol. Soc. Jpn., 67, 375-383.

Philander, S. G., 1989: El Niño, La Niña, and the Southern Oscillation, Academic Press, 308 pp.

Rasmusson, E. M. and T. H. Carpenter, 1982: Variations in tropical sea surface temperature and surface wind fields 
associated with the Southern Oscillation/El Niño.Mon. Weather Rev., 110, 354-384, doi: 10.1175/1520-0493(1982)110<0354:VITSST>2 .0.CO;2. [Link]

Rasmusson, E. M. and J. M. Wallace, 1983: Meteorological aspects of the El Niño/Southern Oscillation. Science, 222, 1195-1202, doi: 10.1126/science.222.4629.1195. [Link]

Smith, T. M. and R. W. Reynolds, 2003: Extended reconstruction of global sea surface temperatures based on COADS data (1854-1997). J. Climate, 16, 1495-1510, doi: 10.1175/1520-0442-16.10.1495. [Link]

Smith, T. M. and R. W. Reynolds, 2004: Improved extended reconstruction of SST (1854-1997). J. Climate, 17, 2466-2477, doi: 10.1175/1520-0442(2004)017<2466:IEROS>2.0.CO;2. [Link]

Tanimoto, Y., N. Iwasaka, K. Hanawa, and Y. Toba, 1993: Characteristic variations of sea surface temperature with multiple time scales in the North Pacific. J. Climate, 6, 1153-1160, doi: 10.1175/1520-0442(1993)006<1153:CVOSST>2.0.CO;2. [Link]

Trenberth, K. E., 1990: Recent observed interdecadal climate changes in the Northern Hemisphere. Bull. Amer. Meteorol. Soc., 71, 988-993, doi: 10.1175/1520-0477-
(1990)071<0988:ROICCI>2.0.CO;2. [Link]

Wang, B. and Q. Zhang, 2002: Pacific-East Asian teleconnection. Part II: How the Philippine Sea anomalous anticyclone is established during El Niño development. J. Climate, 15, 3252-3265, doi: 10.1175/1520-0442(2002)015<3252:PEATPI $>2.0 . C O ; 2$. [Link]

Wang, B., R. Wu, and X. Fu, 2000: Pacific-East Asian teleconnection: How does ENSO affect East Asian climate? J. Climate, 13, 1517-1536, doi: 10.1175/15200442(2000)013<1517:PEATHD > 2.0.CO;2. [Link]

Wang, S. Y. and T. C. Chen, 2008: Measuring East Asian summer monsoon rainfall contributions by different weather systems over Taiwan. J. Appl. Meteorol. Climatol.,47,2068-2080, doi: 10.1175/2007JAMC1821.1. [Link]

Yasunaka, S. and K. Hanawa, 2003: Regime shifts in the Northern Hemisphere SST field: Revisited in relation to tropical variations. J. Meteorol. Soc. Jpn., 81, 415424, doi: $10.2151 / \mathrm{jmsj} .81 .415$. [Link]

Zhang, Y., J. M. Wallace, and D. S. Battisti, 1997: ENSO-like interdecadal variability: 1900-93. J. Climate, 10, 1004-1020, doi: 10.1175/1520-0442(1997)010<1004:ELIV>2.0.CO;2. [Link] 